\title{
PERILAKU KELUARGA DALAM MENCARI PENGOBATAN BAGI ANGGOTA KELUARGA YANG MENGALAMI GANGGUAN JIWA
}

\section{FAMILY BEHAVIORAL HEALTH IN SEEKING AID FOR FAMILY MEMBERS WHO EXPERIENCE MENTAL DISORDERS}

\author{
Siti Qorrotu Aini \\ Kantor Penelitian dan Pengembangan Kabupaten Pati \\ Email: ainiqurrotu85@gmail.com
}

Naskah Masuk: 20 Mei 2014 Naskah Revisi: 28 Mei 2014 Naskah Diterima: 6 Juni 2014

\begin{abstract}
Mental disorders cases in Pati still high. Families providing support in the treatment process in different ways. This study aimed to analyze the family behavior in seeking treatment of mental disorders in Pati. This research used qualitative descriptive methods. The primary data obtained from interviewed by informant consisted of families, community leaders and health workers. Results the study showed that family seeking behavior is different. Some, are still found families which looking for traditional treatment to shamans because ignorance factor that causes mental disorders. Treatment with various shamans did not provide a cure, then the people used modern medical system, that is went to the health service. Modern medical treatment provide healing, but people with mental disorders relaps after back into the family and community.
\end{abstract}

Keywords : family behaviour, seeking treatment, mental disorder

\begin{abstract}
ABSTRAK
Kasus gangguan jiwa di Kabupaten Pati masih tinggi. Keluarga penderita memberikan dukungan dalam proses pengobatan dengan cara yang berbeda-beda. Tujuan penelitan untuk menganalisis perilaku keluarga dalam mencari pengobatan penderita gangguan jiwa di Kabupaten Pati. Penelitian menggunakan metode kualitatif deskriptif. Data primer diperoleh dengan wawancara mendalam terhadap Informan terdiri dari keluarga, tokoh masyarakat dan tenaga kesehatan. Hasil penelitian menunjukkan perilaku keluarga dalam mencari pegobatan penderita gangguan jiwa berbeda-beda. Sebagian, masih ditemukan keluarga yang mencari pengobatan secara tradisional ke dukun karena faktor ketidaktahuan penyebab terjadinya gangguan jiwa. Pengobatan dengan berbagai dukun ternyata tidak memberikan kesembuhan, kemudian masyarakat menggunakan sistem medis modern, yaitu berobat ke pelayanan kesehatan. Pengobatan dengan medis modern memberikan kesembuhan, tetapi setelah penderita gangguan jiwa kembali ke lingkungan keluarga dan masyarakat kembali mengalami kekambuhan.
\end{abstract}

Kata kunci: perilaku keluarga, pencarian pengobatan, gangguan jiwa 


\section{PENDAHULUAN}

Kasus gangguan jiwa di Kabupaten Pati cukup tinggi. Angka gangguan jiwa yang terjadi pada tahun 2013 tercatat 1.650 kasus, dihitung berdasarkan laporan 25 puskesmas dari total keseluruhan yakni 29 Puskesmas (DKK Kabupaten Pati, 2013).

Gangguan jiwa menurut Keputusan Menteri Kesehatan Republik Indonsesia Nomor 220/MENKES/ SK/III/2002 adalah perubahan pada fungsi jiwa yang menyebabkan adanya gangguan pada fungsi jiwa yang menimbulkan penderitaan pada individu atau mengalami hambatan dalam melaksanakan peran sosialnya (Menkes RI, 2002). Hawari (2006) menyatakan tidak dianggap sebagai gangguan yang menyebabkan kematian secara langsung, namun beratnya gangguan tersebut dalam arti ketidakmampuan serta invaliditas baik secara individu maupun kelompok akan menghambat pembangunan, karena mereka tidak produktif dan tidak efisien. Siswono (2001) menyebutkan bahwa hasil studi Bank Dunia tahun 2000 menunjukkan, global burden of disease akibat masalah kesehatan jiwa mencapai $8,1 \%$, jauh lebih tinggi dari tuberkulosis $(7,2 \%)$, kanker $(5,8 \%)$, penyakit jantung $(4,4 \%)$, atau malaria $(2,6 \%)$.

Saat ini penanganan penderita gangguan jiwa masih sangat bervariasi di masyarakat. Pada umumnya penanganan yang dilakukan sesuai dengan persepsi masing-masing dan merasa apa yang telah mereka lakukan adalah sebuah upaya maksimal untuk dapat menyembuhkan si penderita. Brody (2008) menyatakan bahwa kesadaran dan persepsi masyarakat terhadap kesehatan mental berbeda di setiap kebudayaan. Dalam suatu budaya tertentu, orang-orang secara sukarela mencari bantuan dari para profesional untuk menangani gangguan jiwanya. Sebaliknya dalam kebudayaan yang lain, gangguan jiwa cenderung diabaikan sehingga penanganan menjadi buruk, atau di sisi lain masyarakat kurang antusias dalam mencari pertolongan untuk mengatasi gangguan jiwa yang terjadi pada anggota keluarganya, bahkan gangguan jiwa dianggap memalukan atau membawa aib bagi keluarga.

Persepsi yang salah atau mitos terkait gangguan jiwa schizophrenia masih terdapat di Indonesia. Beberapa budaya masyarakat masih mengaitkan penyebab gangguan jiwa diakibatkan oleh kekuatan ghoib. Persepsi tersebut menyebabkan mereka baru mendatangi pelayanan kesehatan atau kesehatan jiwa jika gangguan jiwa yang dialami sudah berat atau bahkan mengganggu orang lain (Directorate Of Mental Health, 2006).

Menurut Maramis (2004), gangguan jiwa dianggap sebagai penyakit yang tidak dapat disembuhkan dan berkaitan dengan dosa atau kejahatan sehingga terkadang pengobatan yang dilakukan pun bersifat brutal dan tidak manusiawi. Keadaan demikian menyebabkan individu yang mengalami gangguan jiwa semakin kronis dan lebih susah untuk disembuhkan. Hal ini menimbulkan beban yang besar bagi pihak yang terkait. Padahal gangguan jiwa pada kenyataannya dapat disembuhkan dengan perawatan dan pengobatan yang benar. Guru Besar Tetap Bidang Keperawatan Jiwa Fakultas Ilmu Keperawatan Universitas Indonesia, Budi Anna Keliat mengatakan gangguan jiwa yang dialami banyak orang dapat disembuhkan dengan perawatan dan obatobatan yang benar (Susanto, 2013)

Penelitian ini bertujuan untuk menggambarkan perilaku keluarga dalam 
mencari pengobatan bagi anggota keluarga yang mengalami gangguan jiwa.

\section{TINJAUAN PUSTAKA}

Perilaku manusia merupakan hasil daripada segala macam pengalaman serta interaksi manusia dengan lingkungannya yang terwujud dalam bentuk pengetahuan, sikap dan tindakan (Sarwono, 2004). Pada dasarnya perilaku dapat diamati melalui sikap dan tindakan juga dalam sikap potensial yakni dalam bentuk pengetahuan, motivasi dan persepsi (Notoatmodjo, 2003).

Perilaku keluarga dalam menghadapi masalah kesehatan bukanlah perilaku yang acak, tetapi perilaku yang selektif terencana dan berpola dalam suatu sistem kesehatan yang merupakan bagian integral dari budaya yang bersangkutan. Seluruh proses dalam mencari pertolongan kesehatan meliputu perangkat konsultan potensial, mulai dari batas-batas keluarga yang informal dan dekat melalui orang awam yang terseleksi, lebih jauh dan mempunyai otoritas, sampai pada tingkat profesionalisme. Hal ini disebut dengan struktur rujukan awam yang meliputi tiga sektor yaitu : sektor populer, sektor tradisonal, dan sektor profesional. Sektor populer melibatkan keluarga, teman, dan tetangga. Pada sektor populer inilah pertama kali kesakitan dikenali dan ditentukan. Perangkat informal ini bisa membantu menafsirkan suatu gejala dan memberi nasehat tentang cara mencari bantuan kesehatan. Keyakinan awam tentang kesehatan dan kesakitan, lebih spesifik mengenai etiologi akan mempengaruhi perilaku mencari bantuan. Sektor tradisional menempati posisi tengah antara sektor awam dengan sektor profesional. Di Indonesia dukun termasuk dalam kelompok tradisional. Tenagatenaga penyembuh tradisional biasanya merupakan warga yang sangat dihormati dalam masyarakatnya. Tenaga penyembuh tradisional dihormati sebagai dukun tradisional. Pada sektor profesional terdiri dari berbagai organisasi profesi di bidang pelayanan kesehatan yang resmi seperti dokter, perawat, dan bidan (Foster dalam Candra dan Dewi, Tt).

\section{METODE PENELITIAN}

Jenis penelitian ini adalah penelitian deskriptif kualitatif untuk menghasilkan data deskriptif berupa kata-kata tertulis atau lisan dari orang-orang dab perilaku yang dapat diamati (Moleong, 2002). Data primer diperoleh dari hasil wawancara dengan keluarga penderita gangguan jiwa dan Petugas Jiwa Puskesmas. Penelitian ini dilaksanakan pada bulan AprilSeptember 2013. Data dianalisis secara deskriptif

\section{HASIL DAN PEMBAHASAN}

\section{Perilaku Pencarian Pengobatan pada Awal Gangguan}

Tindakan atau perilaku merupakan respon internal setelah adanya pemikiran, taggapan, sikap batin dan pengetahuan. Tindakan atau perilaku dipengaruhi oleh keturunan, lingkungan dan pengetahuan (Notoatmodjo, 2003).

Berdasarkan hasil wawancara diketahui bahwa perilaku pencarian pengobatan pada saat awal gangguan jiwa yang dilakukan oleh keluarga berbedabeda, diantaranya adalah dengan membawa penderita ke dukun, dan sebagian lagi berobat ke rumah sakit Jiwa. Perbedaan perilaku ini dipengaruhi oleh pengetahuan keluarga sebagai pengambil keputusan dalam mencari pengobatan penderita. Pengetahuan ini ditentukan berdasarkan tingkat pendidikan keluarga.

Pada kasus \#Dri, \#SD, \#SR dan \#Syt keluarga memutuskan untuk mencari pengobatan ke pelayanan kesehatan formal. Keluarga \#Dri cukup 
berpendidikan, bahkan salah satu kakak Dri adalah seorang kepala desa setempat. Sedangkan ayah \#Dar merupakan seorang pegawai negeri. Saat pertama kali mengetahui gejala sakit, keluarga \#Dri, \#SD, \#Syt membawanya ke Rumah Sakit Umum Daerah dan kemudian di Rujuk ke RSJ Semarang. Seperti pernyataan keluarga \#SD :

"Ketika tau anak saya sakit seperti itu, kami bawa berobat ke rumah sakit. Kalau sekarang tinggal minta obat ke puskesmas. Ndak pernah, ndak pernah ke dukun..."

Selain pendidikan, faktor lain yang menentukan tindakan adalah kejelasan informasi mengenai penyebab terjadinya gangguan. Meskipun keluarga \#SR lulusan $\mathrm{SD}$, akan tetapi mereka mengetahui bahwa perubahan perilaku \#SR terjadi setelah \#SR terjatuh dari tangga di kampus tempat \#SR kuliah. Seperti yang dinyatakan oleh ibu \#SR :

"Ya waktu itu kami jemput dia dari Solo, trus mampir ke Rumah Sakit Jiwa di Semarang. Menurut dokter ada gangguan pada saraf di otaknya"

Lain halnya dengan beberapa keluarga yang lain, lebih memilih pengobatan awal pada orang pinter atau biasa disebut dukun. Keputusan untuk membawa penderita ke dukun, lebih disebabkan karena pada umumnya keluarga tidak mengetahui secara pasti penyebab gangguan jiwa salah satu anggota keluarganya. Keluarga membawa penderita ke dukun, lebih kepada meminta petunjuk atau informasi sekaligus berharap mendapatkan pengobatan dengan biaya yang relatif lebih murah. Beraneka macam informasi dan saran pengobatan yang diperoleh dari dukun dilakukan oleh keluarga masing-masing. Seperti yang diungkapkan oleh ibu \#Tmj :

"Semua cara sudah kami lakukan. Berobat ke dukun sudah tidak terhitung. Di suruh mendokan dengan membaca yasin dan menyembelih ayam juga sudah. Tapi yo ra mengeng (tidak ada hasilnya)"

Pada kasus \#STY, keluarga berkalikali membawa \#STY ke dukun. Sebagian besar dukun memberi informasi bahwa \#STY sakit karena pikirannya sendiri. Memang wataknya keras dan mudah tersinggung. Berdasarkan informasi dari dukun tersebut keluarga berhenti melakukan pengobatan ke dukun.

Peran serta dukun dalam proses pengobatan penderita gangguan jiwa mengindikasikan bahwa faktor budaya masih lekat. Hal ini di di kuatkan oleh pernyataan Foster dalam candra dan Dewi (Tt) bahwa Perilaku keluarga dalam menghadapi masalah kesehatan merupakan bagian integral daribudaya yang bersangkutan. Keyakinan awam tentang kesehatan dan kesakitan, lebih spesifik mengenai penyebab suatu penyakit akan mempengaruhi perilaku mencari bantuan.

\section{Perilaku Pencarian Pengobatan Lanjutan}

Pada umumnya gangguan jiwa khususnya psikotik berlangsung dalam jangka waktu yang relatif lama. Videbeck dalam Purwanto dkk (2013) menyatakan bahwa gangguan psikotik bersifat jangka panjang, oleh karenanya membutuhkan perawatan yang mahal.

Dukungan keluarga sangat dibutuhkan dalam bentuk pendampingan selama proses pengobatan yang relatif lama dan berkelanjutan. Pada penderita psikotik, pengobatan akan lebih efektif jika dilakukan sedini mungkin atau satu 
bulan pertama hingga satu tahun sejak kejadian. Keterlambatan pengobatan akan menyebabkan kondisi penderita semakin kronis dan sulit disembuhkan.

Saat ini, penanganan gangguan jiwa sudah lebih maju. Penderita gangguan jiwa tidak hanya diberikan obat medis (psikofarmaka), tetapi juga terapi-terapi penunjang yang lain. Hawari (2006) menyatakan bahwa penanganan gangguan jiwa bersifat holistik meliputi terapi obat (psikofarmaka), terapi psikologis, sosial, spiritual dan rehabilitasi.

Berdasarkan hasil wawancara dengan informan diketahui bahwa keseluruhan keluarga memberikan dukungan pengobatan secara berkelanjutan. Pengobatan yang berkelanjutan setiap keluarga dilakukan dalam bentuk yang berbeda-beda. Keluarga \#Dri, \#SD, \#SR dan \#Syt dari awal mencari pengobatan melalui pelayanan kesehatan jiwa medis. Pengobatan yang dilakukan dirasakan efektif karena keluarga merasakan perubahan perilaku penderita gangguan jiwa menjadi lebih baik dan terkendali. Hal ini seperti yang dinyatakan oleh keluarga \#Dri :

"Bagus bu. Dia keluar masuk rumah sakit jiwa kurang lebih sudah tujuh kali. Biasanya sepulang dari rumah sakit tingkah lakunya baik. Ya seperti orang normal. Asalkan dia rajin minum obat."

Sedangkan keluarga yang pada awalnya melakukan pengobatan ke dukun, kemudian melanjutkan pengobatan kembali ke dukun, pelayanan kesehatan jiwa medis dan berkonsultasi dengan kyai atau pemuka agama. Keluarga merasa perlu mencoba berbagai cara pengobatan dengan harapan bisa mendapat kesembuhan dari salah satu jenis pengobatan yang dilakukan. Hal ini seperti yang diungkapkan oleh Ibu \#TMJ :

“ya..namanya usaha ya
bu?orang bilang apa, nyaranke
kesana, kesana...ya kami
laksanakan semua.siapa tau
menemukan obatnya. yang
penting bisa sembuh. Ya ganti
lagi dukun ini, dukun sana bagus,
ke puskesmas juga pernah, dokter
saraf juga. Tahun 2012 dijemput
dari rumah sakit jiwa..."

Pada kasus \#SYT, keluarga memutuskan untuk melanjutan pengobatan di pelayanan kesehatan jiwa setelah mendapat keterangan dari para dukun yang didatangi bahwa \#SYT sakit bukan karena hal ghoib tetapi karena kepribadianya. Keluarga mencari pengobatan ke dokter spesialis syaraf atas saran perangkat desa dan kemudian mendapat rujukan untuk ke Rumah Sakit Jiwa. Seperti pernyataan ibu \#SYT :

"Pernah kami bawa berobat ke dokter thomas Pati. Dari sana diberi obat. Pada waktu kembali lagi, disuruh bawa ke rumah sakit jiwa semarang”

Keluarga \#SA melakukan pengobatan lebih kompleks lagi. Selain ke dukun, pelayanan kesehatan jiwa, mereka juga membawa \#SA ke pondok pesantren. Hal ini dilakukan sebagai salah satu upaya terapi pengobatan dari aspek keagamaan. Seperti pernyataan kakak \#SA :

"ke rumah sakit solo pernah, ke orang pintar, dijemput rumah sakit magelang, rumah sakit Semarang, mondok di lasem juga pernah. Sepulang dari RSJ Semarang yang trakhir sudah 
membaik. Dah ingat sholat juga. Tapi karena teringat suaminya, jadi kambuh lagi. Itu sekarang di rante......Ada rencana di pondokke lagi. tapi belum tau nanti...."

Berdasarkan wawancara, secara keseluruhan informan menilai diantara pengobatan yang pernah dilakukan, pegobatan secara formal medis lebih banyak memberikan pengaruh baik pada perilaku penderita. Pada umumnya, pasien kembali kambuh setelah menjalani perawatan di rumah oleh keluarga masingmasing.

Selama proses pencarian pengobatan, dukungan keluarga menjadi salah satu kunci penentu keberhasilan dalam proses pengobatan penderita gangguan jiwa. Sarafino (2006) menyatakan bahwa dukungan keluarga dapat menurun kepada anggota keluarga yang sakit disebabkan lama sakit yang diderita. Lamanya perwatan dan lamanya sembuh menjadi faktor berkurangnya dukungan keluarga.

\section{KESIMPULAN}

\section{Kesimpulan}

Pertolongan awal yang dilakukan
oleh keluarga terhadap anggota
keluarganya yang menderita gangguan
jiwa dalam penelitian ini berbeda-beda
tergantung pengetahuan penyebab
sakit/gangguan yang dialami anggota
keluarganya. Sebagian keluarga membawa
anggota keluarganya yang mengalami
gangguan jiwua ke dukun untuk sekedar
mencari petunjuk sebab penyakit dan
sekaligus mendapatkan obat. Sebagian
keluarga yang lain mencari pengobatan
pada layanan kesehatan medis.
Pertolongan lanjutan yang dilakukan oleh
keluarga juga bervariasi. Sebagian
keluarga dari awal sampai lanjutan
mencari pengobatan ke pelayanan

kesehatan medis, sedangkan sebagian keluarga pada awal mencari pengobatan ke dukun, melanjutkan pengobatan ke pelayanan kesehatan medis (diantaranya dokter syaraf, rumah sakit jiwa dan puskesmas), dan juga ke pondok pesantren dengan bimbingan seorang kyai. Keterlibatan dukun dalam proses pengobatan mengindikasikan bahwa faktor budaya masih menjadi faktor yang menentukan perilaku keluarga dalam mencari bantuan. Diantara berbagai jenis pengobatan yang dijalani penderita gangguan jiwa, pengobatan yang dirasakan paling berpengaruh terhadap perilaku anggota keluarga penderita gangguan jiwa adalah terapi di rumah sakit jiwa. Kekambuhan penderita kembali terjadi justru ketika penderita kembali ke rumah masing-masing.

\section{Saran}

Pelayanan kesehatan jiwa di masyarakat diharapkan tidak hanya menunggu pasien datang berobat ke fasilitas kesehatan jiwa. Kegiatan pelayanan kesehatan jiwa di Puskesmas perlu dikembangkan. Peningkatan pengetahuan gangguan jiwa dan fasilitas pengobatannya perlu lebih diprioritaskan.

\section{DAFTAR PUSTAKA}

Brody, E. B. 2008. Pengaruh Kebudayaan Terhadap Pemahamam Dan Pelayanan Masyarakat. http://www.rsjlawang.com. Diakses 15 Januari 2011.

Candra, I. W. dan Ni Ketut Ari P. D. Tt. Perilaku Keluarga Dalam Mencari Pertolongan Kesehatan Bagi Anggota Keluarganya Yang Mengalami Gangguan Jiwa Denpasar. http://www.google.co.id/url?q=http: //jurusankeperawatanbali.com/attac hments/article/131/ARTIKEL\%2520 \%2520I\%2520WAYAN\%2520CAN 
DRA.doc\&sa $=U \& e i=J B 6 V U 4 y \_C d$

GSuASjkYLYCQ\&ved $=0 C B c Q F j A A$ $\& u s g=A F Q j C N E z X 2 O P T d U V x Z R o$ d8yV6ZIl-_lzBw. Diakses 20 Mei 2014.

Dinas Kesehatan Kabupaten Pati. 2013. Rekapitulasi Data Gangguan Jiwa Di Kabupaten Pati Triwulan ke-2 tahun 2013. Pati.

Directorate of Mental Health Care. 2006.

Final Report Development of National Policy and Strategy For Mental Hospital. Indonesia : Ministry of Healt.

Hawari, D. 2006. Pendekatan Holistik Pada Gangguan Jiwa Skizofrenia. Jakarta : Kedokteran Universitas Indonesia.

Maramis, W. F. 2004. Catatan Ilmu Kedokteran Jiwa. Surabaya : Airlangga University Press

Menteri Kesehatan Republik Indonesia. 2002. Keputusan Menteri Kesehatan Republik Indonesia Nomor: 220/ MENKES/SK/III/2002, Tentang Pedoman Umum Tim Pembina, Tim Pengarah, Tim Pelaksana Kesehatan Jiwa Masyarakat. http://www.goggle.com. Diakses 14 Januari 2013.

Moleong, Lexy J. 2002. Metodologi Penelitian Kualitatif. Bandung : PT Remaja RosdaKarya.
Notoatmodjo, S. 2003. Pendidikan Dan Perilaku Kesehatan. Jakarta : PT. Rineka Cipta.

Purwanto, D. dkk. 2013. Masalah Psikososial Pasung Pasien Gangguan Jiwa. Bandar Lampung : Kepaniteraan Klinik Kedokteran Jiwa Rumah Sakit Jiwa Provinsi Lampung.

Sarafino, E. P. 2006. Health Psychology. New York : John Willey and Sons, Inc.

Sarwono, S. 2007. Sosiologi Kesehatan. Yogyakarta : UGM Press.

Siswono. 2001. Sangat Besar, Beban akibat Gangguan Jiwa. http://www.gizi.net. Diakses 12 Januari 2013.

Susanto, A. 2013. Gangguan Jiwa Dapat Disembuhkan dengan Terapi yang Benar. http://health.liputan6.com/read/547 360/gangguan-jiwa-dapatdisembuhkan-dengan-terapi-yangbenar. Diakses 15 Mei 2013.

\section{BIODATA PENULIS}

Siti Qorrotu Aini, lahir 5 Agustus 1985 di kota Pati Jawa Tengah. Sarjana (S1) Universitas Diponegoro Semarang Jurusan Psikologi Tahun 2009. Bekerja sebagai peneliti di Kantor Penelitian dan Pengembangan Kabupaten Pati. 